University of Nebraska - Lincoln

DigitalCommons@University of Nebraska - Lincoln

Uniformed Services University of the Health

Sciences

U.S. Department of Defense

2011

\title{
Effectiveness of battlefield-ethics training during combat deployment: a programme assessment
}

Christopher H. Warner

Command and General Staff College, christopher.h.warner@us.army.mil

George N. Appenzeller

US Army Medical Activity Alaska

Angela Mobbs

5th Special Forces Group Fort Bragg

Jessica R. Parker

Winn Army Community Hospital

Carolynn M. Warner

Munson Army Health Clinic

See next page for additional authors

Follow this and additional works at: https://digitalcommons.unl.edu/usuhs

Part of the Medicine and Health Sciences Commons

Warner, Christopher H.; Appenzeller, George N.; Mobbs, Angela; Parker, Jessica R.; Warner, Carolynn M.; Grieger, Thomas; and Hoge, Charles W., "Effectiveness of battlefield-ethics training during combat deployment: a programme assessment" (2011). Uniformed Services University of the Health Sciences. 70. https://digitalcommons.unl.edu/usuhs/70

This Article is brought to you for free and open access by the U.S. Department of Defense at DigitalCommons@University of Nebraska - Lincoln. It has been accepted for inclusion in Uniformed Services University of the Health Sciences by an authorized administrator of DigitalCommons@University of Nebraska Lincoln. 


\section{Authors}

Christopher H. Warner, George N. Appenzeller, Angela Mobbs, Jessica R. Parker, Carolynn M. Warner, Thomas Grieger, and Charles W. Hoge 


\section{Effectiveness of battlefield-ethics training during combat deployment: a programme assessment}

Christopher H Warner, George N Appenzeller, Angela Mobbs, Jessica R Parker, Carolynn M Warner, Thomas Grieger, Charles W Hoge

\begin{abstract}
Summary
Background Breakdowns in the ethical conduct of soldiers towards non-combatants on the battlefield are of grave concern in war. Evidence-based training approaches to prevent unethical conduct are scarce. We assessed the effectiveness of battlefield-ethics training and factors associated with unethical battlefield conduct.
\end{abstract}

Methods The training package, based on movie vignettes and leader-led discussions, was administered 7 to 8 months into a 15-month high-intensity combat deployment in Iraq, between Dec 11, 2007, and Jan 30, 2008. Soldiers from an infantry brigade combat team (total population about 3500) were randomly selected, on the basis of company and the last four digits of each soldier's social security number, and invited to complete an anonymous survey 3 months after completion of the training. Reports of unethical behaviour and attitudes in this sample were compared with a randomly selected pre-training sample from the same brigade. The response patterns for ethical behaviour and reporting of ethical violations were analysed with chi-square analyses. We developed two logistic regression models using self-reported unethical behaviours as dependent variables. Factors associated with unethical conduct, including combat experiences and post-traumatic stress disorder (PTSD), were assessed with validated scales.

Findings Of 500 randomly selected soldiers 421 agreed to participate in the anonymous post-training survey. A total of 397 soldiers of the same brigade completed the pre-training survey. Training was associated with significantly lower rates of unethical conduct of soldiers and greater willingness to report and address misconduct than in those before training. For example, reports of unnecessary damage or destruction of private property decreased from $13.6 \%$ $(54$ of $397 ; 95 \%$ CI $10 \cdot 2-17 \cdot 0)$ before training to $5 \cdot 0 \%$ (21 of $421 ; 2 \cdot 9-7 \cdot 1)$ after training (percent difference $-63 \cdot 2 \%$; $\mathrm{p}<\mathbf{0 . 0 0 0 1}$ ), and willingness to report a unit member for mistreatment of a non-combatant increased from $36.0 \%$ (143 of 397; 31·3-40 · ) to $58 \cdot 9 \%(248$ of $421 ; 54 \cdot 2-63 \cdot 6$; percent difference $63 \cdot 6 ; \mathrm{p}<0 \cdot 0001)$. Nearly all participants (410 [97\%]) reported that training made it clear how to respond towards non-combatants. Combat frequency and intensity was the strongest predictor of unethical behaviour; PTSD was not a significant predictor of unethical behaviour after controlling for combat experiences.

Interpretation Leader-led battlefield ethics training positively influenced soldiers' understanding of how to interact with and treat non-combatants, and reduced reports of ethical misconduct. Unethical battlefield conduct was associated with high-intensity combat but not with PTSD.

Funding None.

\section{Introduction}

The ethical conduct of US military service members engaged in combat operations in Iraq or Afghanistan came to the forefront of public attention with the events of Abu Ghraib (2004), Haditha (2006), and other highly publicised cases. ${ }^{1,2}$ In some of these cases, including recent allegations of murder of non-combatants by a sniper team in Iraq and a group of soldiers in a Stryker unit, unethical conduct has been attributed to the stresses of combat or post-traumatic stress disorder (PTSD). ${ }^{3,4}$ Unethical conduct has been a concern in previous wars.

In 2006, ethical issues were included for the first time in the annual theatre-wide Mental Health Assessment Team (MHAT) survey of the wellbeing of US soldiers deployed in Iraq. ${ }^{5}$ The survey specifically addressed the issue of battlefield ethics and the adequacy of battlefieldethics training in the preparation of soldiers for combat operations in Iraq. The 2006 MHAT survey showed that less than $50 \%$ of soldiers were willing to report a member of their unit for ethical violations, $13 \%$ reported damaging a non-combatant's personal property, and $6 \%$ reported hitting or kicking non-combatants unnecessarily (table 1). ${ }^{5}$ Additionally, soldiers with high levels of combat exposure or who met criteria for PTSD reported high levels of unethical conduct, although a systematic statistical analysis of factors associated with ethical misconduct was not reported. ${ }^{5}$

The findings of the MHAT survey led to a recommendation for the development of a battlefield-ethics training programme. However, at the time of the next MHAT survey in mid 2007, no systematic training programme had been developed, and the 2007 MHAT assessment showed levels of unethical conduct similar to that reported in the 2006 survey (table 1). ${ }^{6}$

The unchanged levels of unethical conduct reported in the 2007 MHAT survey prompted the Commanding General of the Multi-National Division-Center in Iraq to develop and implement a battlefield-ethics training
Lancet 2011; 378: 915-24 See Comment page 857 Command and General Staff College, Fort Leavenworth, KS, USA (C H Warner MD); US Army Medical Activity Alaska, Fort Wainwright, AK, USA (G N Appenzeller MD); 5th Special Forces Group Fort Bragg, NC, USA (A Mobbs PsyD); Warrior Restoration Center, Winn Army Community Hospital, Fort Stewart, GA, USA (J R Parker PsyD); Munson Army Health Clinic, Fort Leavenworth, KS, USA (C M Warner MD); Uniformed Services University of Health Sciences, Bethesda, MD, USA (Prof T Grieger MD); and Center for Psychiatry and Neurosciences, Walter Reed Army Institute of Research, Silver Spring, MD, USA (CW Hoge MD)

Correspondence to: Dr Christopher H Warner, US Army Medical Activity-Alaska, Fort Wainwright, AK 99703, USA christopher.h.warner@ us.army.mil 


\begin{tabular}{|c|c|c|}
\hline & MHAT $2006^{5}(\mathrm{~N}=1320)$ & MHAT $2007^{6}(\mathrm{~N}=2195)$ \\
\hline \multicolumn{3}{|l|}{ Unethical behaviours* } \\
\hline Insulted and/or cursed non-combatants in their presence & $490(37 \%)$ & $740(34 \%)$ \\
\hline Damaged and/or destroyed private property when it was not necessary & $173(13 \%)$ & $312(14 \%)$ \\
\hline Physically hit/kicked a non-combatant when it was not necessary & $77(6 \%)$ & $138(6 \%)$ \\
\hline Members of my unit "modify" the Rules of Engagement in order to accomplish the mission & $143(11 \%)$ & $171(8 \%)$ \\
\hline Members of my unit "ignore" the Rules of Engagement in order to accomplish the mission & $79(6 \%)$ & $99(5 \%)$ \\
\hline \multicolumn{3}{|l|}{ Reporting of ethical violations $\dagger$} \\
\hline I would report a unit member for the mistreatment of a non-combatant & $478(36 \%)$ & $738(34 \%)$ \\
\hline I would report a unit member for injuring or killing an innocent non-combatant & $581(44 \%)$ & $891(41 \%)$ \\
\hline I would report a unit member for unnecessarily destroying private property & $411(31 \%)$ & $656(30 \%)$ \\
\hline I would report a unit member for stealing from a non-combatant & $499(38 \%)$ & $748(34 \%)$ \\
\hline I would report a unit member for violating the Rules of Engagement & $479(36 \%)$ & $777(35 \%)$ \\
\hline I would report a unit member for not following General Orders & $483(37 \%)$ & $764(35 \%)$ \\
\hline \multicolumn{3}{|c|}{$\begin{array}{l}\text { Data are number (\%). MHAT=Mental Health Assessment Team. *Unethical behaviours that occurred one or more times were reported. †Willingness to report ethical } \\
\text { violations were assessed by reporting whether soldiers agreed or strongly agreed with each statement. }\end{array}$} \\
\hline
\end{tabular}

programme for all soldiers under his command. In response to the Commander's directive, a training development team was created, which was led by the Division Psychiatrist with representatives for the Staff Judge Advocate (legal), Division Surgeon (medical), Adjutant (personnel), and Chaplain. During the training development, experts in the specialties of both military and civilian ethics training were consulted.

The team did a review of military and medical reports and publications about ethical training, international humanitarian law, civilian protection in war, and combat stress behaviours. Many reports discussed the importance of ethical behaviour on the battlefield, the effect of violations, and the influence of group conformity and obedience on decision making in ethical dilemmas. ${ }^{7-15}$ One report ${ }^{13}$ cited a need for systematic training, noting that it should be a continuing process, and suggested that training should focus on enhancing moral reasoning and judgment and instilling particular values (eg, integrity, professionalism, responsibility). Reports preferentially focused on treatment of prisoners of war, ethical issues related to the provision of medical care, or scenarios with high ambiguity for which one could make strong arguments both for or against particular decisions (eg, whether to shoot an innocent child or risk the child revealing the location of soldiers on a secret mission behind enemy lines)..$^{14,15}$ However, few studies presented models for effective education with routine scenarios involving non-combatants encountered by soldiers on a day-to-day basis, and no specific outcome measures existed that were relevant to current operations in Iraq or Afghanistan until the publication of the MHAT survey results. Additionally, data about factors associated with battlefield ethical violations were scarce, which might inform training efforts.
This review led to the development and implementation of a practical, scenario-based, battlefield-ethics training programme for use in theatre. We aimed to assess the effectiveness of the battlefield-ethics training programme, and to establish whether a change occurred in soldiers' reports of how they treated non-combatants, attitudes towards unethical conduct, and their willingness to report ethical violations. We also assessed the association of PTSD, combat exposure, and other variables with unethical conduct on the battlefield.

\section{Methods \\ Study design and participants}

The training programme was developed in October, 2007, and implemented between Dec 11, 2007, and Jan 30, 2008. We compared the answers from anonymous cross-sectional surveys done before and after battlefield-ethics training in randomly selected soldiers from one brigade combat team during a 15-month deployment to Iraq (total brigade population about 3500). The pre-training survey included all respondents from the brigade who had participated in the annual theatre-wide MHAT survey in August, 2007, about 3-4 months into a 15-month deployment and before the training was undertaken. Training was given 7-8 months into the deployment, and then the second cross-sectional survey was administered by the study investigators 3-4 months after the training with the same methods used in the 2007 MHAT survey. In addition to the MHAT questions, we included questions to assess the training and factors associated with unethical conduct. To ensure comparable 3-month observation periods, survey questions asked before training referred to behaviours occurring since the beginning of deployment. Questions asked after training referred to behaviours in the most recent 3 months of the deployment. Permission to undertake this study was obtained from the in-theatre 
Panel 1: Overview of the in-theatre battlefield-ethics training programme

\section{Summary}

- Task: conduct battlefield-ethics training.

- Format: video or slide directed discussion in a leader-led chain-teaching format.

- Purpose: to promote adherence, protect against unnecessary suffering and collateral damage, and to promote the humane treatment of non-combatants.

- Conditions: leaders are provided with a training disc with slides and videos and a script of key talking points to discuss in each section. Total training time is $60-90 \mathrm{~min}$.

\section{Introduction}

- During this section the leader covers the key points of the Army Values, basic principles of the Law of War, the Soldier Rules, and the indicators of potential misconduct. The leader also reviews the key data about battlefield ethical behaviour from the studies done by the Mental Health Assessment Team.

\section{Treatment of non-combatants}

- Scene (movie clip: Platoon; start 47 min $20 \mathrm{~s}$, length 2 min 45 s): unit searching a village immediately following a significant enemy engagement.

- Key discussion items: coping with stress, balancing excessive versus prudent force, Rules of Engagement, and preventing maladaptive stress induced responses.

- Warning signs discussed included cursing, destroying property for no reason, or killing of animals.

Looting, pillaging, and treatment of wounded

- Scene (movie clip: Patriot; start 26 min 20 s, length $3 \mathrm{~min} 40 \mathrm{~s}$ ): depicts a civilian providing aid and assistance to soldiers from both sides.

- Key discussion items: soldiers might feel they earned the right to loot and pillage, or commanders might do this to instil fear; however, these short-term gains have long-term consequences and violate the Law of War. The Geneva Conventions make clear that enemies wounded in action are no longer enemy combatants and should be provided medical care.

\section{Killing non-combatants}

- Scene 1 (movie clip: Platoon; start 50 min: 22 s, length $2 \min 15 \mathrm{~s}$ ): rage attack against villagers.
- Scene 2 (movie clip: Black Hawk Down; start 61 min 35 s, length $25 \mathrm{~s}$ ): determining if a child is an enemy combatant.

- Key discussion items: in most instances, the killing of non-combatants is clearly wrong and illegal and must be dealt with through the military judicial system, it hurts the mission and the unit. However, in some instances substantial ambiguity exists. Determining if a child or adolescent is a non-combatant can sometime be difficult. Focus is on identification of non-combatants versus enemy combatants.

\section{Rules of Engagement}

- Scene (movie clip: Three Kings; start 0 min 55 s, length $1 \mathrm{~min} 7 \mathrm{~s}$ ): soldiers are being indecisive about how to engage and interact with possible enemy combatants.

- Key discussion items: soldiers always have the innate right to protect themselves; however, the Rules of Engagement provide guidelines for soldiers' actions. Failure to follow the rules could place the mission at risk. Emphasis is placed on understanding the current Rules of Engagement for the operational theatre.

\section{Reporting ethical violations}

- Scene (movie clip: Home of the Brave; start 11 min $45 \mathrm{~s}$, length $2 \mathrm{~min}$ ): soldiers are involved in a continuing urban battle where a civilian is wounded and killed in the fog of war.

- Key discussion items: data about soldiers' willingness to report potential violations and attitudes towards investigations; the importance of soldiers' understanding that investigations after combat incidents are not just about determining wrong-doing but are also about providing reassurance that the proper steps and actions are taken, and garnering the lessons that can be learned.

\section{Warning signs and protective factors}

- Warning signs and associated factors contributing toward unethical behaviour: use of drugs and alcohol, high combat exposure, unaddressed mental health problems, poor equal-opportunity climate, failure of expected support, poor unit cohesion, low confidence in unit leadership.

- Protective factors: leadership, high unit cohesion, early recognition and addressing of combat operational stress, sleep, rest and refit, effective communication, after-action debriefing.
Institutional Review Board (IRB), which included monitoring and approval both from senior medical researchers in-theatre, and the IRB at Brooke Army Medical Center, San Antonio, TX, USA, that was responsible for oversight of in-theatre medical research.

\section{Procedures}

The battlefield-ethics training team conferred with the US Army Judge Advocate General Center and School, the Walter Reed Army Institute of Research, and several civilian experts in ethics, and chose to expand on the foundation of Law of War (including the Geneva Conventions) and the current US Army Values through structured discussions of specific movie vignettes involving ethical dilemmas. ${ }^{16,17}$ The focus of the training related to concerns identified in the MHAT surveys or serious violations that had come to media attention (eg, treatment of non-combatants, looting and pillaging, killing non-combatants, Rules of Engagement, and willingness to report ethical violations). ${ }^{5,6}$

In the 2007 MHAT focus groups, many soldiers reported a desire to hear from those who had previously 
deployed and from their unit leaders about how they should handle ethical dilemmas. ${ }^{6}$ Furthermore, many soldiers reported that they did not find behavioural training with "typical powerpoint briefings" effective. Consequently, the training that was developed consisted of a leader-led interactive programme with brief video vignettes to highlight key learning points and serve as starting points for discussions. A military legal review permitted the use of clips from popular movies for this educational purpose, and unit commanders approved the content.

The division implemented a chain-teaching format in which senior leaders taught their immediate subordinate leaders. The subordinate leaders then taught their own subordinate leaders until the training involved all military personnel. Training sessions were done in small groups to promote discussion among those who served in combat together. To ensure that the training was standardised throughout, unit leaders were provided with a script that included key questions and discussion points for each video vignette. The leaders were encouraged to link these discussions to current situations and issues that the unit was facing. An overview of the training programme is provided in panel 1 .

For the pre-training comparison sample, 397 soldiers were identified as belonging to the study brigade from a total of 2195 who completed MHAT surveys in brigades throughout theatre. These soldiers were identified on the basis of unit identifiers in the otherwise anonymous MHAT survey database. ${ }^{6}$ This dataset, gathered 3-4 months into the brigade's deployment, contained only the responses to demographic, combat exposure, and battlefield-ethics questions from the larger MHAT survey.

The sampling methods of the 2007 MHAT survey have been described previously. ${ }^{6}$ Briefly, 25 soldiers from randomly selected line and support companies within brigade combat teams throughout Iraq were selected. Although most of the MHAT data gathered in Iraq allowed for convenience sampling in randomly selected companies, a random method of soldier selection in each of the selected companies was used in the brigade chosen for this study, on the basis of the last four digits of each soldier's social security number. Soldiers who were approached for participation in the MHAT survey were informed of the voluntary and anonymous nature of the survey, which was administered according to a protocol approved by the Walter Reed Army Institute of Research institutional review board. ${ }^{6}$

For the recruitment of participants to the post-training sample, which was done with a protocol approved by the in-theatre institutional review board, 500 soldiers were randomly selected from the same brigade that participated in the 2007 MHAT study with the same random selection methods. Specifically, 25 soldiers were selected from each Alpha, Bravo, Charlie, and Delta companies of the five subordinate battalions within the brigade, for a total of 500. All soldiers for whom the last four numbers of their social security numbers began with 3,6 , or 9 had their names placed on individual cards in a container with no identifiers visible and 25 were drawn from the container. Once identified, the selected soldiers were approached by the unit's medical provider and invited to complete an anonymous paper survey. Soldiers were informed that participation was voluntary, would remain anonymous, and that their participation or nonparticipation would have no negative effect on them. To ensure the anonymity of participants in the study, no personal identifying information was collected on the survey and the completed surveys were placed in a sealed envelope and locked drop box at the medical aid station, which was accessible only by the investigators. Because this survey was anonymous, a requirement for signed consent was waived, and completion of the survey was classed as consent.

Both surveys, done before and after battlefield-ethics training, included the same questions related to ethical behaviour and reporting of ethical violations, combat exposure, and demographic information (age, rank, sex, education, deployment history, time spent outside the forward operating base)., ${ }^{5,6}$ The PTSD checklist-military (PCL-M) 17 and the patient health questionnaire (PHQ) 9, which have been validated and widely used in military and veteran populations, were used to assess for PTSD and depression in the soldiers who completed the survey after training. ${ }^{18-21}$ Additionally, nine statements about soldiers' attitudes towards the battlefield-ethics chain-teaching programme were included in the post-training survey.

The combat exposure section included 15 statements in which respondents were asked how many times a series of combat events occurred during deployment, with a five-point response from 1 (never) to 5 (10 times or more) for each event. The sections on ethical behaviours and reporting of ethical violations included a subset of the questions from the 2007 MHAT survey in which respondents were asked to rate seven questions, on a five-point scale from 1 (never) to 5 (five times or more), about how often they engaged in a specific unethical behaviour in the past 90 days. Additionally, the soldiers were asked to rate how much they disagree or agree with an additional 11 statements about attitudes toward reporting ethical violations on a five-point scale from 1 (strongly disagree) to 5 (strongly agree). Questions related to ethical conduct focused on attitudes and specific behaviours that were somewhat subjective (ie, insulting non-combatants, damaging property, or hitting or kicking a non-combatant "when it was not necessary"), to encourage honest reporting on the anonymous surveys, as had been done in previous MHAT surveys.

The PCL-M is a 17-item self-report checklist, directly adapted from the PTSD criteria in the Diagnostic and Statisical Manual IV. The checklist is keyed specifically to stressful military experiences. Soldiers were asked to rate how much they have been bothered in the past month by various experiences on a five-point scale 
ranging from 1 (not at all) to 5 (extremely). Scoring was accomplished by summing the responses of each question with the total score ranging from 17 to 85 . The PCL-M has been validated and widely used in military populations, and a score of 50 or greater has been deemed optimum for the identification of PTSD in population-level research..$^{18,19}$

The PHQ 9 is a nine item, self-administered version of the depression module of the primary care evaluation of mental disorders. ${ }^{20}$ This test assesses the nine diagnostic criteria for depression on a scale 0 (not at all) to 3 (nearly every day) and is used widely in the military. ${ }^{21}$ When the test is used for screening, the individual responses are summed (scale range $0-34$ ). Scores of 5, 10, 15, and 20 have high reliability and validity for mild, moderate, moderately severe, and severe depression, and a cutoff of 10 was selected for this study. ${ }^{20}$

\section{Statistical analyses}

All data were entered into an SPSS (version 12.02) database. The primary focus was on descriptive statistics including the reported rates of ethical behaviours among soldiers, willingness to report ethical violations, prevalence of probable PTSD on the basis of the established cutoff scores on the PCL-M, prevalence of depressive symptoms on the basis of the PHQ 9, and number of combat exposures. Pre-training and post-training survey responses were compared using chi-square analyses.

We developed two logistic regression models using self-reported unethical behaviours as dependent variables, including soldiers' participation in insulting or cursing at non-combatants and mistreatment of non-combatants (defined as either unnecessary damage or destruction of non-combatant property or unnecessarily hitting or kicking non-combatants). The independent variables that were assessed included age (less than 25 vs 25 years or older), sex, rank, completion of previous combat deployments (any vs none), highest level of education, current symptoms suggestive of depression or PTSD, time spent outside the forward operating base (greater than $20 \mathrm{~h}$ per week versus $20 \mathrm{~h}$ or less per week), and a sum of combat exposures. Both individual associations between dependent and independent variables and adjusted associations were assessed.

\section{Role of the funding source}

No industry grants or financial support were used in this project. Study design, data collection, data analysis, data interpretation, and writing of the report were completed entirely by the study investigators and they had full access to all data in the study. The corresponding author had full access to all data in the study and had final responsibility to submit for publication.

\section{Results}

The training was completed in all brigades under the Multi-National Division-Center Iraq, including about

\begin{tabular}{|c|c|c|c|c|}
\hline & $\begin{array}{l}\text { Before } \\
\text { battlefield-ethics } \\
\text { training }(\mathrm{N}=397)\end{array}$ & $\begin{array}{l}\text { After } \\
\text { battlefield-ethics } \\
\text { training }(\mathrm{N}=421)\end{array}$ & $\begin{array}{l}\text { Chi square } \\
\text { (degrees of } \\
\text { freedom }=1 \text { ) }\end{array}$ & p value \\
\hline \multicolumn{5}{|l|}{ Sex } \\
\hline Female & $49(12 \%)$ & $61(14 \%)$ & 0.635 & 0.43 \\
\hline Male & $348(88 \%)$ & $360(86 \%)$ & 0.635 & 0.43 \\
\hline \multicolumn{5}{|l|}{ Age (years) } \\
\hline $17-25$ & $183(46 \%)$ & $173(41 \%)$ & 1.882 & 0.17 \\
\hline$\geq 26$ & $214(54 \%)$ & $248(59 \%)$ & 1.882 & 0.17 \\
\hline \multicolumn{5}{|l|}{ Prior deployment history } \\
\hline 0 & $191(48 \%)$ & $216(51 \%)$ & 0.712 & 0.40 \\
\hline 1 & $132(33 \%)$ & $125(30 \%)$ & 1.041 & $0 \cdot 31$ \\
\hline$\geq 2$ & $74(19 \%)$ & $80(19 \%)$ & 0.002 & 0.96 \\
\hline \multicolumn{5}{|l|}{ Rank } \\
\hline E1-E4* & $230(58 \%)$ & $218(52 \%)$ & 2.879 & 0.09 \\
\hline E5-E9† & $143(36 \%)$ & $167(40 \%)$ & 1.005 & $0 \cdot 32$ \\
\hline Officers or Warrant Officers & $24(6 \%)$ & $36(8 \%)$ & 1.537 & 0.22 \\
\hline \multicolumn{5}{|l|}{ Education } \\
\hline GED or high school & NA & $192(46 \%)$ & NA & NA \\
\hline Some college & NA & $170(40 \%)$ & NA & NA \\
\hline College graduate & NA & $59(14 \%)$ & NA & NA \\
\hline \multicolumn{5}{|l|}{ Mental health } \\
\hline PTSD or depression & $71(18 \%)$ & $92(22 \%)$ & 1.776 & 0.18 \\
\hline \multicolumn{5}{|l|}{ Combat exposures } \\
\hline Being attacked or ambushed & $199(50 \%)$ & $213(51 \%)$ & 0.004 & 0.95 \\
\hline Small arms fire & $146(37 \%)$ & $163(39 \%)$ & $0 \cdot 250$ & 0.62 \\
\hline Saw dead bodies or human remains & $129(33 \%)$ & $170(40 \%)$ & $5 \cdot 145$ & 0.02 \\
\hline Handling human remains & $87(22 \%)$ & $100(24 \%)$ & $0 \cdot 294$ & 0.26 \\
\hline Witnessing violence & $101(25 \%)$ & $131(31 \%)$ & $2 \cdot 966$ & 0.09 \\
\hline Seeing dead Americans & $114(29 \%)$ & $157(37 \%)$ & $6 \cdot 403$ & 0.01 \\
\hline $\begin{array}{l}\text { Knowing someone seriously injured } \\
\text { or killed }\end{array}$ & $207(52 \%)$ & $249(59 \%)$ & $3 \cdot 784$ & 0.05 \\
\hline IED exploded nearby & $113(29 \%)$ & $141(34 \%)$ & $2 \cdot 184$ & 0.14 \\
\hline Hostile reactions from civilians & $122(31 \%)$ & $128(30 \%)$ & 0.001 & 0.98 \\
\hline Threatened and unable to respond & $118(30 \%)$ & $95(23 \%)$ & $5 \cdot 070$ & 0.02 \\
\hline Shooting or firing & $75(19 \%)$ & $109(26 \%)$ & $5 \cdot 347$ & 0.02 \\
\hline $\begin{array}{l}\text { Clearing or searching homes or } \\
\text { buildings }\end{array}$ & $109(28 \%)$ & $114(27 \%)$ & 0.002 & 0.96 \\
\hline Being wounded or injured & $23(6 \%)$ & $31(7 \%)$ & 0.582 & $0 \cdot 45$ \\
\hline $\begin{array}{l}\text { Seeing ill or wounded women } \\
\text { or children }\end{array}$ & $77(19 \%)$ & $91(22 \%)$ & $0 \cdot 488$ & $0 \cdot 45$ \\
\hline Encountering sniper fire & $61(15 \%)$ & $83(20 \%)$ & $2 \cdot 374$ & 0.12 \\
\hline \multicolumn{5}{|c|}{ Time outside of the forward operating base } \\
\hline$\geq 20 \mathrm{~h}$ & $153(39 \%)$ & $139(33 \%)$ & $2 \cdot 479$ & 0.12 \\
\hline \multicolumn{5}{|c|}{$\begin{array}{l}\text { Data are number (\%). NA=not available. GED=general equivalency diploma. PTSD=post-traumatic stress disorder. } \\
\text { IED=improvised explosive device. *These ranks included Private (recruit; E1), Private (E2), Private First Class (E3), and } \\
\text { Specialist or Corporal (E4). †These ranks include Sergeant (E5), Staff Sergeant (E6), Sergeant First Class (E7), Master } \\
\text { Sergeant or First Sergeant (E8), Sergeant Major, or Command Sergeant Major (E9). }\end{array}$} \\
\hline
\end{tabular}

3500 soldiers in the brigade combat team selected for this study. Of these soldiers, 500 were randomly selected to participate in the post-training survey, and $421(84 \%)$ voluntarily chose to participate. The sample included mostly male enlisted soldiers, who were on 


\begin{tabular}{|c|c|c|c|c|c|}
\hline & $\begin{array}{l}\text { Number before training } \\
(\% ; 95 \% \mathrm{Cl})^{*}\end{array}$ & $\begin{array}{l}\text { Number after training } \\
(\% ; 95 \% \mathrm{Cl}) \dagger\end{array}$ & $\begin{array}{l}\text { Percent } \\
\text { difference }\end{array}$ & $\begin{array}{l}\text { Chi square } \\
\text { (degrees of } \\
\text { freedom=1) }\end{array}$ & p value \\
\hline \multicolumn{6}{|l|}{ Questions on perceived adequacy of training (agree or strongly agree) } \\
\hline The training I received in the proper (ethical) treatment of non-combatants was adequate & $287(72 \cdot 3 \% ; 67.9-76 \cdot 7)$ & $399(94 \cdot 8 \% ; 92 \cdot 6-97 \cdot 0 \%)$ & $31 \cdot 1$ & 74.67 & $<0.0001$ \\
\hline I encountered ethical situations in which I didn't know how to respond & $119(30 \cdot 0 \% ; 25 \cdot 5-34 \cdot 5)$ & $47(11 \cdot 2 \% ; 8 \cdot 2-14 \cdot 2 \%)$ & $-62 \cdot 7$ & $43 \cdot 54$ & $<0.0001$ \\
\hline I received training that made it clear how I should behave towards non-combatants & $295(74 . \% ; 70 \cdot 0-78 \cdot 6)$ & $410(97 \cdot 4 \% ; 95 \cdot 9-98 \cdot 9 \%)$ & $31 \cdot 1$ & $89 \cdot 49$ & $<0.0001$ \\
\hline \multicolumn{6}{|l|}{ Actual behaviours and experiences during deployment (one or more times) } \\
\hline Insulted and/or cursed non-combatants in their presence & $118(29 \cdot 7 \% ; 25 \cdot 2-34 \cdot 2)$ & $87(20 \cdot 7 \% ; 16 \cdot 8-24 \cdot 5 \%)$ & $-30 \cdot 3$ & 8.45 & 0.004 \\
\hline Damaged and/or destroyed private property when it was not necessary & $54(13 \cdot 6 \% ; 10 \cdot 2-17 \cdot 0)$ & $21(5 \cdot 0 \% ; 2 \cdot 9-7 \cdot 1 \%)$ & $-63 \cdot 2$ & $17 \cdot 19$ & $<0.0001$ \\
\hline Physically hit/kicked a non-combatant when it was not necessary & $24(6 \cdot 1 \% ; 3 \cdot 7-8 \cdot 4)$ & $14(3 \cdot 3 \% ; 1 \cdot 6-5 \cdot 0 \%)$ & $-45 \cdot 9$ & 2.82 & 0.093 \\
\hline Witnessed the brutality/mistreatment of a non-combatant by a unit member & $34(8 \cdot 6 \% ; 5 \cdot 8-11 \cdot 3)$ & $12(2 \cdot 9 \% ; 1 \cdot 3-4 \cdot 4 \%)$ & $-66 \cdot 2$ & $11 \cdot 52$ & 0.0007 \\
\hline Stopped a fellow unit member from mistreating a non-combatant & $20(5 \cdot 0 \% ; 2 \cdot 9-7 \cdot 2)$ & $12(2 \cdot 9 \% ; 1 \cdot 3-4 \cdot 4 \%)$ & $-42 \cdot 0$ & 2.05 & 0.152 \\
\hline Members of my unit "modify" the Rules of Engagement to accomplish the mission & $26(6 \cdot 6 \% ; 4 \cdot 1-9 \cdot 0)$ & $19(4 \cdot 5 \% ; 2 \cdot 5-6 \cdot 5 \%)$ & $-31 \cdot 8$ & 1.26 & 0.261 \\
\hline Members of my unit "ignore" the Rules of Engagement to accomplish the mission & $13(3 \% ; 1 \cdot 5-5 \cdot 0)$ & $11(2 \cdot 6 \% ; 1 \cdot 1-4 \cdot 1 \%)$ & $-21 \cdot 2$ & 0.13 & 0.724 \\
\hline \multicolumn{6}{|l|}{ Attitudes toward ethical conduct (agree or strongly agree) } \\
\hline I would report a unit member for the mistreatment of a non-combatant & $143(36 \cdot 0 \% ; 31 \cdot 3-40 \cdot 7)$ & $248(58 \cdot 9 \% ; 54 \cdot 2-63 \cdot 6 \%)$ & 63.6 & 41.98 & $<0.0001$ \\
\hline I would report a unit member for injuring or killing an innocent non-combatant & $165(41 \cdot 6 \% ; 36 \cdot 7-46 \cdot 4)$ & $271(64 \cdot 4 \% ; 59 \cdot 8-68 \cdot 9 \%)$ & 54.8 & $41 \cdot 79$ & $<0.0001$ \\
\hline I would report a unit member for unnecessarily destroying private property & $131(33 \cdot 0 \% ; 28 \cdot 4-37 \cdot 6)$ & $250(59 \cdot 4 \% ; 54 \cdot 7-64 \cdot 1 \%)$ & $80 \cdot 0$ & $56 \cdot 11$ & $<0.0001$ \\
\hline I would report a unit member for stealing from a non-combatant & $146(36 \cdot 8 \% ; 32 \cdot 0-41 \cdot 5)$ & $259(61 \cdot 6 \% ; 56 \cdot 9-66 \cdot 2 \%)$ & $67 \cdot 4$ & $49 \cdot 06$ & $<0.0001$ \\
\hline I would report a unit member for violating the Rules of Engagement & $148(37 \cdot 3 \% ; 32.5-42 \cdot 0)$ & $261(62.0 \% ; 57 \cdot 4-66 \cdot 6 \%)$ & $66 \cdot 2$ & 48.94 & $<0.0001$ \\
\hline I would report a unit member for not following General Orders & $156(39 \cdot 3 \% ; 34 \cdot 5-44 \cdot 1)$ & $256(60 \cdot 8 \% ; 56 \cdot 2-65 \cdot 4 \%)$ & $54 \cdot 7$ & $36 \cdot 97$ & $<0.0001$ \\
\hline Torture should be allowed if it will save the life of a soldier & $154(38 \cdot 8 \% ; 34 \cdot 0-43 \cdot 6)$ & $115(27 \cdot 3 \% ; 23 \cdot 1-31 \cdot 6 \%)$ & -29.6 & 11.68 & 0.0006 \\
\hline Torture should be allowed to gather important information about insurgents & $135(34 \cdot 0 \% ; 29 \cdot 4-38 \cdot 7)$ & $96(22 \cdot 8 \% ; 18 \cdot 8-26 \cdot 8 \%)$ & $-32 \cdot 9$ & $12 \cdot 11$ & 0.0005 \\
\hline
\end{tabular}

their first combat deployment (table 2). Most (404 [96\%]) acknowledged completing the unit battlefield-ethics training programme, which was consistent with training logs kept by the brigade that showed $100 \%$ compliance with the training requirement. More than half reported that they had either been attacked or ambushed or knew someone who had been injured or killed in Iraq (table 2). Chi-square analyses showed that the pre-training and post-training groups had comparable demographics, mental health concerns, and time outside the forward operating base. The post-training group had higher levels of several combat experiences than did the pre-training group, which was an expected finding.

More than a fifth of post-training survey respondents met screening criteria for depression or PTSD, which was comparable to the prevalence in the pre-training sample (table 2). 42 (10\%) soldiers met screening criteria for PTSD as defined by a PCL-M score of 50 or higher, while $79(19 \%)$ had symptoms of depression as defined by a PHQ-9 score of 10 or higher. The mean PCL-M score was 28.6 (SD 14.0, 95\% CI 27.3-29.9) and the mean PHQ 9 score was 4.8 (SD 5.6, 95\% CI 4·2-5.4). A third of participants reported that they spent more than $20 \mathrm{~h}$ per week outside the forward operating base, which was comparable to that before training (table 2).

Most soldiers who completed the post-training survey reported some form of combat exposure (367 [87\%]), with the overall sample averaging $11 \cdot 8$ (SD $12 \cdot 3,95 \% \mathrm{CI}$ $10 \cdot 5-13 \cdot 1)$ exposures on a scale of $0-45$ exposures. Nearly all of those who spent more than $20 \mathrm{~h}$ per week outside the forward operating base reported combat exposure (134 [96\%]), and many of those who spent most of their time on the forward operating base also reported combat exposures (233 [83\%]). However, we identified a notable difference in the mean number of combat exposures per soldier between those who spent more than $20 \mathrm{~h}$ per week outside the base camp (19.1 [SD 14 -3, 95\% CI 16.7-21·5]) and the other soldiers $(8 \cdot 2[9 \cdot 3,7 \cdot 1-9 \cdot 3)$. All but one of the soldiers who met screening criteria for PTSD reported combat exposures during deployment.

Table 3 compares the ethical attitudes and behaviours reported by soldiers 3-4 months after training completion and those reported before training (which referred to the 3-4 month period from the beginning of the deployment). Significant increases were seen in soldiers' perceptions of their preparedness for encountering non-combatants (table 3). Decreased rates of unethical conduct were noted in all categories after training, with significant reductions in reports of insulting or cursing at non-combatants, unnecessary damage or destruction of private property, or witnessing mistreatment by a fellow unit member. Significant reductions were seen in all categories of attitudes related to reporting of a fellow soldier for ethical misconduct (table 3). 


\begin{tabular}{|c|c|c|c|c|c|c|c|c|c|c|}
\hline & \multicolumn{5}{|c|}{ Insulted or cursed at non-combatants } & \multicolumn{5}{|c|}{$\begin{array}{l}\text { Damaged or destroyed property or hit or kicked a } \\
\text { non-combatant when it was not necessary }\end{array}$} \\
\hline & \multirow[t]{2}{*}{$\mathrm{n}(\%)$} & \multicolumn{2}{|c|}{ Unadjusted } & \multicolumn{2}{|l|}{ Adjusted ${ }^{*}$} & \multirow[t]{2}{*}{$n(\%)$} & \multicolumn{2}{|l|}{ Unadjusted } & \multicolumn{2}{|l|}{ Adjusted ${ }^{*}$} \\
\hline & & Odds ratio & pvalue & Odds ratio & p value & & Odds ratio & p value & Odds ratio & p value \\
\hline Depression (PHQ $9 \geq 10$ ) & $25(28.7 \%)$ & 2.09 & 0.008 & 1.47 & 0.285 & $12(42 \cdot 9 \%)$ & 3.65 & 0.001 & 2.88 & 0.051 \\
\hline PTSD (PCL-M $\geq 50)$ & $18(20 \cdot 7 \%)$ & $3 \cdot 37$ & $<0.0001$ & 1.64 & 0.277 & $8(28 \cdot 6 \%)$ & $4 \cdot 22$ & 0.002 & 1.00 & 0.994 \\
\hline $\begin{array}{l}>20 \text { h outside the } \\
\text { forward operating base }\end{array}$ & $46(52 \cdot 9 \%)$ & $2 \cdot 87$ & $<0.0001$ & 1.45 & 0.201 & $16(57 \cdot 1 \%)$ & 2.89 & 0.007 & 1.11 & 0.832 \\
\hline $\begin{array}{l}\text { Combat exposure } \\
\text { (continuous variable) }\end{array}$ & $84(96 \cdot 6 \%)$ & 1.068 & $<0.0001$ & 1.06 & $<0.0001$ & $28(100 \cdot 0 \%)$ & 1.08 & 0.000 & 1.07 & $<0.0001$ \\
\hline
\end{tabular}

PHQ 9=patient health questionnaire 9. PTSD=post-traumatic stress disorder. PCL-M=PTSD checklist-military. *Adjusted analyses included depression, PTSD, time working outside the forward operating base, combat exposure, and demographics (age, sex, prior deployment, rank, and education).

Table 4: Association of mental health problems, time working outside the forward operating base, and combat exposure with unethical behaviours

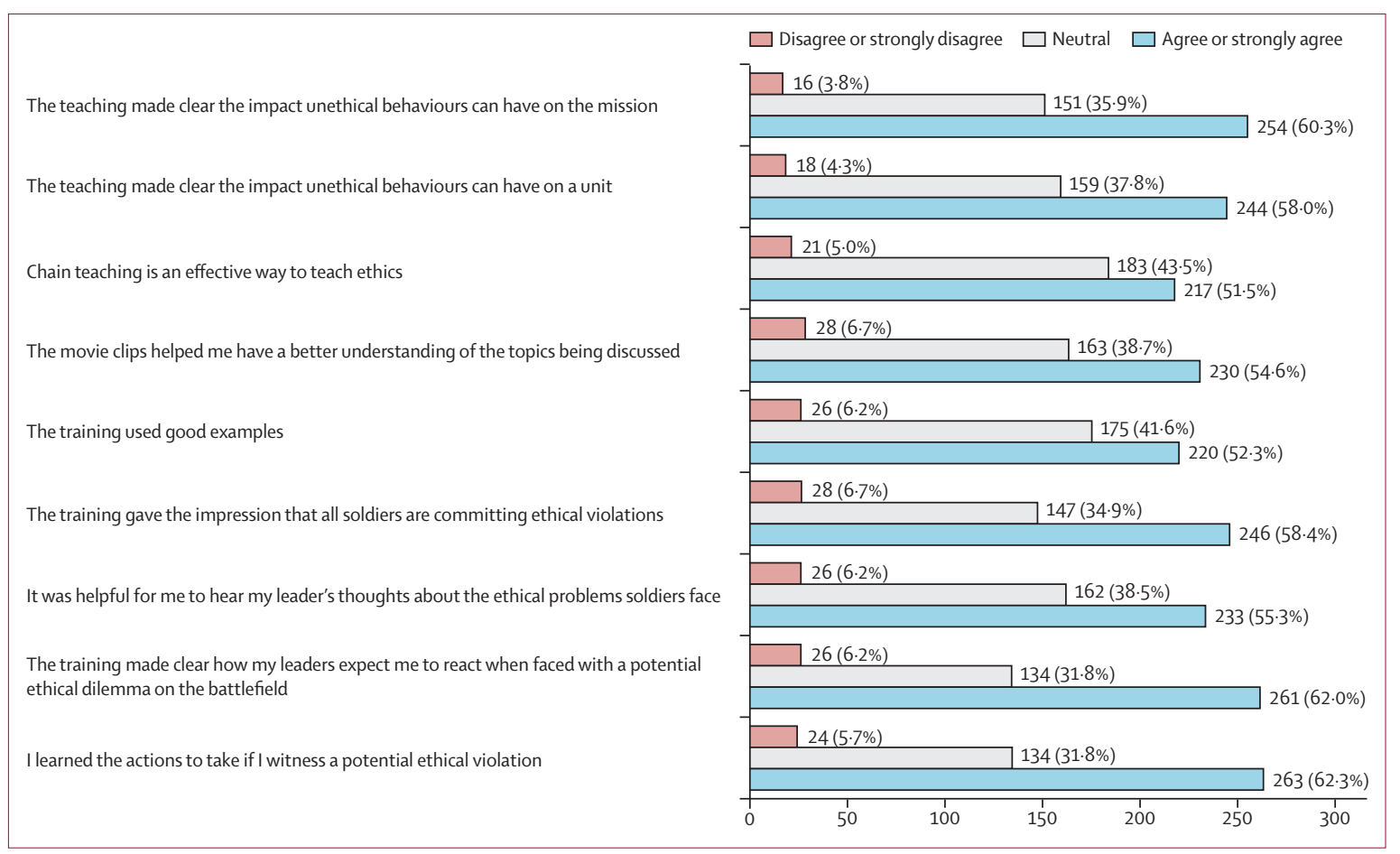

Figure: Soldiers' attitudes toward battlefield-ethics training $\mathrm{N}=421$.

When the post-training ethical behaviours were examined, about a fifth of soldiers responded that they had participated in insulting or cursing at non-combatants, compared with about a third of those before training; reports of damaging or destroying private property when it was not necessary decreased from nearly $14 \%$ to $5 \%$, and reports of witnessing brutality or mistreatment of noncombatants by a unit member decreased from nearly $9 \%$ to $3 \%$ (table 3 ). Significant increases were seen in the willingness of soldiers to report ethical violations (table 3 ).

The unadjusted univariate logistic regression models (table 4) showed that a positive screening for PTSD or depression, spending more than $20 \mathrm{~h}$ outside the forward operating base, and high-intensity combat (on the basis of the exposure score) all showed significant associations with mistreatment of non-combatants (ie, unnecessary damage to property or unnecessarily hitting or kicking non-combatants). However, when these associations were adjusted in a model that combined these variables together with demographics (age, sex, rank, education, and history of prior deployment), only combat exposure remained a significant predictor of mistreatment of non-combatants. PTSD, time outside the base-camp, and combat exposure did predict yelling and cursing at non-combatants, although combat exposure again greatly attenuated the strength of these associations in adjusted analyses.

The figure outlines the soldiers' attitudes towards the training programme. Most considered the format to be 
effective and nearly two-thirds noted that they learned what actions to take and understood the effect that ethical violations can have on a unit's mission. We did subgroup analyses to compare the perceptions of training with PTSD, time outside the operating base, and combat exposures; no significant differences or trends were noted in any of these analyses.

\section{Discussion}

Results from our assessment of the battlefield-ethics training programme suggest that soldiers' behaviours and attitudes towards the treatment of non-combatants can be positively influenced through leader-led training discussions (panel 2). The conduct of US military personnel on the battlefield has potential far-reaching consequences on tactical mission effectiveness and the strategic success of entire operations with coalition partners. Two past surveys done during the Iraq deployment in 2006 and 2007, suggested that 13-14\% of US soldiers reported damaging or destroying private property and $6 \%$ reported hitting or kicking a noncombatant when it was not necessary (table 1).,5 This type of behaviour has serious moral and legal ramifications, and can damage military relations with local populations and jeopardise the ability of the US and coalition forces from other nations to achieve military objectives.

One of the important findings of our study is that PTSD was not associated with unethical conduct after controlling for combat experiences. The intensity of direct combat seemed to be the strongest predictor of unethical conduct, which is borne out also by many anecdotes of combat veterans who describe intense and sometimes uncontrollable rage in association with horrific events, such as losing a close team member. ${ }^{22}$ The soldiers who spent more than $20 \mathrm{~h}$ per week outside the fortified and protected forward operating bases averaged a greater number of combat exposures than did

\section{Panel 2: Research in context}

\section{Systematic review}

We searched both military reports and MEDLINE for reports published between Jan 1, 1970, and Oct 1, 2007, with the search terms "military ethics", "battlefield ethics", "combat ethics", "soldier ethics", "ethics education", "ethical training", "treatment of non-combatants", "international humanitarian law", "civilian protection in war", and "combat stress".

\section{Interpretation}

Our findings have important implications for how military leaders prepare their forces for military operations ranging from peacekeeping to combat. Furthermore, unethical battlefield conduct was associated with high-intensity combat but not with PTSD, countering a commonly held belief that PTSD is a cause of such behaviour. Additional studies are needed to refine, disseminate, and further assess the effectiveness of battlefield-ethics training. those who spent less time outside the base. This group also interacted more frequently with the civilian populace, placing them in situations where noncombatant mistreatment could occur. The results suggest that training in battlefield ethics should be prioritised, especially for those units expected to engage in highintensity direct combat and who will have the most interaction with the civilian, non-combatant population.

The degree to which ethical attitudes and reported behaviours could be modified through training is an encouraging finding. The training was well received by soldiers. The brief video clips provided a framework for discussion of topics relevant to the day-to-day scenarios that these soldiers were encountering, sometimes including ambiguous and difficult ethical dilemmas. The chain teaching provided a method for unit leaders to give guidance on how they expected their subordinates to respond to ethically challenging situations and also allowed for direct discussion between participants about situations they had actually encountered in their work. Furthermore, the leaders' personal engagement in the training emphasised the priority of the topic, and modelled what was expected throughout the rest of the deployment. The use of a script ensured that the key teaching points were delivered consistently across the different leader-led discussions.

Further studies are needed to refine the battlefield-ethics training methods, improve the sustainability and reproducibility of the training effects, and establish the most effective training implementation plans. On the basis of the initial feedback used in this intervention, we strongly suggest that future training includes engagement of unit leaders with their subordinates on these issues. The use of popular movie clips seemed to be helpful in facilitating discussion. However, the success of this programme was probably not related to the specific vignettes selected, but rather to the discussion by leaders that led to a cultural change in which unit awareness of ethical issues and leadership expectations improved.

An important limitation of this study was the absence of a randomised or experimental design, which was not possible in the operational environment, and therefore the outcomes and conclusions were observational and dependent on the comparability of the pre-training and post-training samples. Data from both samples were gathered from within the same unit with the same random sampling methods, and with comparable timeframes of reference. Analysis confirmed that data for demographics and exposure to direct combat of the two samples were comparable, which was also representative of the theatre-wide MHAT survey sample. Soldiers' perceptions of training, including the use of movie vignettes and leader-led discussions, were positive, with many soldiers attributing improved understanding of how to handle ethical dilemmas to training.

Soldiers' attitudes could have changed during deployment because of experience or time in theatre, and not 
directly because of training. However, previous theatrewide MHAT surveys showed no improvement in ethical attitudes and behaviour associated with time in theatre. ${ }^{6}$ Furthermore, the relation between unethical behaviours and number of combat exposures would suggest an expected worsening in attitudes and behaviour with increased time in theatre because of the likelihood of additional exposure rather than the recorded improvement in this sample.

Linkage of pre-training and post-training responses for individual soldiers and control for possible confounding from temporal changes in responses (eg, improved attitudes over time as a result of experience in theatre, independent of training) was not possible because of the anonymous nature of reporting. However, an additional post-hoc analysis of all soldiers who completed the 2007 MHAT survey showed that longer time in theatre was associated with higher rates of unethical behaviours and reduced willingness to report a team member for mistreatment of a non-combatant (Col Paul Bliese, Walter Reed Army Institute of Research, Silver Spring, MD, USA, personal communication). ${ }^{6}$ Thus, the significant improvement in outcomes seen between pretraining and post-training assessments in the study brigade is particularly noteworthy.

Another study limitation is the reliance on selfreported measures and the subjectivity of some of the questions (eg, which behaviours soldiers perceived as "necessary" in the combat environment). However, the consistency and strength of associations across the various outcome measures supports the conclusion that the training had a positive effect on both ethical attitudes and actual behaviours.

Individuals might have underreported misconduct, avoided participation in the survey out of fear that they might face disciplinary action if their survey responses were identifiable, or responded in a manner that was perceived as desirable to the unit leaders and military environment. However, the anonymous reporting, precautions to ensure that surveys were not accessible to unit peers or leaders, and use of questions that focused on attitudes and somewhat subjective behaviours probably encouraged honest reporting. Evidence suggests that soldiers are much more willing to report sensitive mental-health concerns on anonymous surveys than in screening surveys used in non-anonymous confidential clinical settings. ${ }^{23}$ Furthermore, soldiers' responses were consistent in this study sample as compared with previous theatre-wide anonymous surveys, which used the same questions. The survey sampling design and protection of soldiers' identities with anonymous surveys were identical for the pretraining and post-training groups, and the post-training survey was administered 3-4 months after training rather than in close proximity. Therefore, differences attributable to social desirability or different levels of concern about anonymity are unlikely.
Our finding that battlefield-ethics training with leaderled discussions positively influenced soldiers' behaviours and attitudes towards the treatment of non-combatants has implications for the conduct of many peacekeeping and combat operations worldwide. Although battlefield ethical conduct is judged to be crucial to mission success, and training is increasingly being included in the curriculum of military organisations internationally, ${ }^{7,13,24}$ we are not aware of any other systematic programme assessment. The results of this study can inform training programmes worldwide, including a North Atlantic Treaty Organization (NATO) initiative, chartered in 2009, to develop and implement moral dilemma training for all NATO forces..$^{25}$ Our study is the first published study to provide both potential methods for preventing unethical conduct and associated factors for unethical battlefield conduct.

Emphasis should be placed on training those with high levels of combat exposure, and should include experientially-based leader-led discussions.

\section{Contributors}

CHW, GNA, AM, and TG undertook the search of published works. CHW, GNA, AM, CMW, and TG designed the study. CHW coordinated the study with the IRB. CHW, GNA, and AM coordinated with the unit and collected the data in Iraq. CHW, GNA, CMW, JRP, and CWH contributed to the analysis and interpretation of the data. CHW drafted the report with substantial input from CWH; all co-authors critically revised the report.

\section{Conflicts of interest}

We declare that we have no conflicts of interest.

\section{Acknowledgments}

Our work was part of our employment with US Federal Government and is therefore in the public domain. The views stated in this Article are those of the authors and do not represent the views or the policy of the US Department of Defense. No industry grants or financial support were used in this project. We thank Paul Bliese for providing the MHAT survey data.

References

1 US Army Regulation 15-6 Investigation of the 800th Military Police Brigade. Fort McPherson GA, Headquarters Third US Army, 2004. http://images.military.com/ContentFiles/Taguba.pdf (accessed Aug 1, 2011).

2 McGirk T. Collateral damage or civilian massacre in Haditha? Time Magazine, Mar 19, 2006. http://www.time.com/time/world/ article/0,8599,1174649,00.html (accessed Aug 1, 2011).

3 Junod T. The six letter word that changes everything. Esquire, June 11, 2008. http://www.esquire.com/features/ michael-hensley-0708 (accessed Feb 28, 2011).

4 Associated Press. PTSD defense may delay murder trial of Iraq Veteran. Army Times, Oct 19, 2010. http://www.armytimes.com/ news/2010/10/ap-army-iraq-veteran-nicholas-horner-murder-trialdelay-possible-101910 (accessed Feb 28, 2011).

5 Mental Health Advisory Team (MHAT-IV). Operation Iraqi Freedom 05-07 (Nov 17, 2006). http://www.armymedicine.army.mil/reports/ mhat/mhat_iv/mhat-iv.cfm (accessed June 22, 2011).

6 Mental Health Advisory Team (MHAT-V). Operation Iraqi Freedom 06-08 (Feb 14, 2008). http://www.armymedicine.army.mil/reports/ mhat/mhat_v/mhat-v.cfm (accessed June 22, 2011).

7 Robinson P. Ethics training and development in the military. Parameters 2007; 37: 22-36.

8 Baumann D. Military ethics: a task for armies. Military Med 2007; 172: S34-38.

9 Kaplan S. Yoga and the battlefield of ethics: highlighting an infusion model for ethics education. Sci Eng Ethics 2006 12: $391-98$.

10 Miller JJ. Squaring the circle: teaching philosophical ethics in the military. J Military Ethics 2004; 3: 199-215. 
11 Vetter S. Understanding human behavior in time of war. Military Med 2007; 172: S7-10.

12 Fleischmann ST. Teaching ethics more than an honor code. Sci Eng Ethics 2006; 12: 381-89.

13 van Baarda TA, Verweij D. Military ethics: the Dutch approach — a practical guide. Leiden, the Netherlands: Brill, 2006: 2-24.

14 Verweij D, Hofhuis K, Soeters J. Moral judgment within the armed forces. J Military Ethics 2007; 6: 19-40.

15 Howe E. Dilemmas in military medical ethics since 9/11. Kennedy Inst Ethics J 2003; 13: 175-88.

16 US Army. Field manual 1 The Army. Washington, DC: Department of the Army, 2005: 1-22.

17 US Army. Field manual 27-10 change 1, the law of land warfare. Washington, DC: Department of the Army, 1976.

18 Bliese PD, Wright KM, Adler AB, Cabrera O, Castro CA, Hoge CW. Validating the primary care posttraumatic stress disorder screen and the posttraumatic stress disorder checklist with soldiers returning from combat. J Consult Clin Psychol 2008; 76: 272-81.

19 Terhakopian A, Sinaii N, Engel CC, Schnurr PP, Hoge CW. Estimating population prevalence of posttraumatic stress disorder: an example using the PTSD checklist. J Traumatic Stress 2008; 21: $290-300$.
20 Kroenke K, Spitzer RL, Williams JB. The PHQ-9: validity of a brief depression severity measure. J Gen Intern Med 2001; 16: 606-13.

21 Thomas JL, Wilk JE, Riviere LA, McGurk D, Castro CA, Hoge CW. Prevalence of mental health problems and functional impairment among active component and national guard soldiers 3 and 12 months following combat in Iraq. Arch Gen Psychiatry 2010; 67: 614-23.

22 Hoge CW. Once a warrior always a warrior. Guilford, CT: Globe Pequot Press, 2010: 154-69.

23 Warner CH, Appenzeller GN, Grieger TA, et al. Importance of anonymity to encourage honest reporting in mental health screening after combat deployment. Arch Gen Psychiatry (in press).

24 Robinson P. Ethics education in the military. In: Robinson P, De Lee N, Carrick D. eds. Ethics Education in the Military. Burlington VT: Ashgate, 2008: 1-12.

25 Moral Dilemmas and Mental Health Problems (HFM-179), May, 2009, http://www.rto.nato.int/ACTIVITY_META. asp?ACT=HFM-179 (accessed June 1, 2011). 